\title{
LOCURA Y TRANSGRESIÓN EN LOS CUENTOS FANTÁSTICOS DE ANTONIO DE HOYOS Y VINENT
}

\section{Mohamed Ben Slama}

Université de Monastir

\begin{abstract}
RESUMEN: El presente trabajo trata de estudiar la combinación entre lo fantástico y la locura en cuatro cuentos del escritor madrileño Antonio de Hoyos y Vinent (1884-1940), recogidos en su libro Los cascabeles de Madama Locura (1916). Pertenece a una tendencia que se puso de moda en España en la segunda mitad del siglo XIX, debido a los avances en psiquiatría y la influencia de las figuras emblemáticas de la literatura fantástica en los escritores españoles, y que se intensificó con el cambio de siglo, coincidiendo con el Modernismo, que es la corriente en la que se enmarca nuestro autor. Nuestro objetivo es estudiar hasta qué punto Hoyos y Vinent siguió en estos cuentos las pautas de lo fantástico interior a través de la introspección de la mente enferma.
\end{abstract}

PALABRAS CLAVE: locura, transgresión, cuento fantástico, Modernismo, cambio de siglo

ABSTRACT: This paper attempts to study the correlation between madness and fantasy in four tales of the Spanish writer Antonio de Hoyos y Vinent (1884-1940) from his book Los cascabeles de Madama Locura (1916). This is a trend that became fashionable in Spain in the second half of the nineteenth century due to advances in psychiatry and the influence of emblematic figures of the fantastic literature in Spanish writers' works. It was yet intensified with the turn of the century coinciding with Modernism, the movement to which our author is attributed. Our goal is to study how Hoyos y Vinent followed, in these particular tales, the inner fantastic masterlines through introspection of the sick mind.

KEY WORDS: madness, transgression, fantastic tale, Modernism, turn of century

El tema de la locura y de los desórdenes mentales empieza a cobrar protagonismo en la narrativa española de corte fantástico a partir de la segunda mitad del siglo XIX, ${ }^{1}$ a través de los relatos de Galdós y Pardo Bazán, entre otros. Sigue avanzando con más fuerza coincidiendo con el cambio del siglo, que es "el momento en que el género fantástico presenta con mayor intensidad la fusión de lo sobrenatural y lo inconsciente” (Roas y Casas, 2008: 13) y lo encontramos en los relatos de Silverio Lanza, Miguel Sawa, Pío Baroja, Miguel de Unamuno, etc. Con el Modernismo, encuentra una "reivindicación modernista del mundo interior y de los sentimientos" (Casas, 2008: 359), además, un terreno propicio para

\footnotetext{
${ }^{1}$ Véase $\mathrm{M}^{\mathrm{a}}$ de los Ángeles Ezama Gil: “Cuentos de locos y literatura fantástica: Aproximación a su historia entre 1868 y 1910”, Anthoropos, 154-155 (1994), 77-82.
} 
desarrollarse mediante las patologías mentales (Phillips-López, 2003) a través de unos textos en los que la perturbación mental se manifiesta en sus múltiples facetas: "sueños, delirio, locura, desdoblamiento, influencia magnética" (Casas, 2008: 364). De esta forma, el cultivo del tema de la locura traduce el gran cambio que sufrió la literatura fantástica, que pasó de reflejarse de un modo exterior a presentarse en una forma interior. Lo que caracteriza la literatura modernista, en este aspecto, es "el marcado interés por la psicología" (PhillipsLópez, 2003: 40), que "está vinculado al desarrollo intenso y decisivo de esta disciplina como ciencia positiva que se ha ido independizando de la metafísica" (Phillips-López, 2003: 40). De esta forma, asistimos a un interés mutuo entre la literatura y la psicología. Herrero Cecilia $(2002)^{2}$ incluye los temas de locura en lo fantástico interior y para-psicológico, puesto que la percepción que tiene el personaje de los acontecimientos misteriosos es subjetiva: "el peligro proviene del interior del propio individuo" (Casas, 2008: 364). La importancia del tema de la locura y su relación con la transgresión radica en que, desde el punto de vista estético, es el fenómeno más enigmático y más rico de todos los fenómenos irracionales, tal como apunta Ezama $(1994)^{3}$ quien, además, habla de un tipo de literatura en la que la mente perturbada ocupa el centro de atención en las fantasías literarias.

Por otra parte, los críticos se han puesto de acuerdo en que la combinación de lo fantástico y la neurosis en los cuentos fantásticos españoles de finales del siglo XIX y principios del siglo XX se debe a dos aspectos: los avances en psiquiatría y la influencia de las grandes figuras de la literatura fantástica. Así, los grandes progresos psiquiátricos en la segunda mitad del siglo XIX abrieron nuevas posibilidades a los autores fantásticos "para ir más allá del mundo racional, para sumergirse en el lado oscuro de la mente y sacar a la luz los miedos, los deseos reprimidos, las frustraciones, con una intención, además, claramente subversiva en relación al plácido y ordenado mundo burgués" (Roas y Casas, 2008: 15). En cuanto a las grandes figuras de la literatura fantástica, cuyos relatos sirvieron de referentes para los escritores españoles en lo que se refiere a la locura, mencionamos a Hoffmann ${ }^{4}$, quien fue el primero en "explorar la dimensión interior de lo fantástico, entendida como manifestación de los miedos y pasiones más ocultos del ser humano, contemplados siempre como una amenaza para éste" (Roas, 2002: 33). Sin embargo, estas manifestaciones se reflejan con más abundancia en los relatos de Poe, ${ }^{5}$ como "El gato negro", "La caída de la

\footnotetext{
${ }^{2}$ José Herrero Cecilia considera que los temas relacionados con lo fantástico interior son fenómenos subjetivos relacionados con el interior del personaje. Los divide en varios temas: el tema del doble; la misteriosa realidad del sueño y su proyección sobre la experiencia vivida por el personaje; la enigmática realidad de la locura y lo fantástico para-psicológico; el tema del Amor y la Muerte. Este último suele ir unido al de la mujer fatal o al de la mujer ideal; el aparecido (fantasma, espectro, visión obsesiva que persigue al personaje, etc.); la misteriosa transfiguración del espacio y el tiempo desde la perspectiva desconcertada del personaje (este tema va unido con frecuencia al de los sueños, las alucinaciones o visiones); el tema de la obra apócrifa o la magia de la extraña repercusión de una historia de ficción sobre la vida real del personaje.

${ }^{3} \mathrm{M}^{\mathrm{a}}$ de los Ángeles Ezama, "Cuentos de locos y literatura fantástica: Aproximación a su historia entre 1868 y 1910", Op. cit.; se basa en el ensayo de Gwenhaël Ponnau (1987): Les folies de la littérature fantastique. París, Editions du CNRS.

${ }^{4}$ Véase David Roas (2002): Hoffmann en España. Recepción e influencias. Madrid, Biblioteca Nueva.

${ }^{5}$ Véase Santiago Rodríguez Guerrero-Strachen (1999): Presencia de Edgar Allan Poe en la literatura española del siglo XIX. Valladolid, Universidad de Valladolid, 204-215; David Roas (2011): La sombra del cuervo. Edgar Allan Poe y la literatura fantástica española del siglo XIX. Madrid, Devenir Ensayo; $\mathrm{M}^{\mathrm{a}}$ de los Ángeles González Miguel (2000): E.T.A. Hoffmann y E.A. Poe. Estudio comparado de su narrativa breve. Valladolid, Universidad de Valladolid.
} 
casa Usher" y "El corazón delator", en los que apreciamos el "estudio de una mente humana en curso de desintegración" (Roas, 2011: 103), y que se caracterizan por "una hipersensibilidad nerviosa que les lleva a ver la realidad de una manera distinta a lo que es normal" (Guerrero-Strachan, 1999: 204). No se puede pasar por alto la figura de Maupassant, quien cultivó este género y quien era muy leído y traducido en España en esos años, sobre todo su relato más famoso "El Horla".

Antes de pasar a analizar los cuentos seleccionados, es oportuno señalar que el efecto fantástico se perdería de haberse recurrido a la locura o a la alucinación para explicar el fenómeno sobrenatural, como afirma Molina Porras (2006), quien considera que "la explicación onírica o la locura, anulan cualquier duda y quitan corporeidad a los fenómenos sobrenaturales" (2006: 30). Desde luego, en los cuentos objeto de estudio, la perturbación del personaje no tiene por qué anular el carácter fantástico del relato, cuyo interés consiste en adentrarse "en la conciencia de unos hombres que no siguen la pauta de la lógica común" (Molina Porras, 2006: 30). Los cuentos que vamos a estudiar pertenecen a Los cascabeles de Madama Locura (1916), de Antonio de Hoyos y Vinent (1884-1940), quien es, como muchos de sus coetáneos, uno de los autores que intentaron reflejar la combinación entre la neurosis y lo fantástico haciendo gala de un seguimiento de todo lo sucedido en el siglo XIX dentro y fuera de España. Comellas Aguirrezábal retoma una declaración de Hoyos y Vinent de la novela El banquete de Minotauro, en la que el último dice que "el cerebro humano, cuanto más enfermo, cuanto más deformado y podrido está, más nobles, bellos y altos pensamientos destila" (2001: 43). En este tipo de relatos, la perplejidad y el desconcierto del autor no terminan cuando termina el cuento. Son unos textos que, más allá de la definición de Todorov sobre los diferentes componentes que hacen que un relato pertenezca a lo fantástico puro ${ }^{6}$, cumplen con dos requisitos fundamentales: "la irrupción de lo sobrenatural en el mundo real y, sobre todo, la imposibilidad de explicarlo de forma razonable" (Roas, 2001: 18).

Mi análisis se centrará en cuatro títulos: "Una noche bajo el terror", "Una aventura de amor", "Un cadáver sin identificar" (bajo la sección "El más allá") y "Un amor de ultratumba" (bajo la sección "El jardín de Hécate"). Entre todos los cuentos del libro, son los que más se ajustan a lo puramente fantástico o, como afirma Martín Rodríguez, son "los cuentos más claramente fantásticos" (2015: 21), y por ende, son los únicos del libro que presentan la locura como eje central de la trama. Reproducen una muestra del tipo de literatura cultivada por Antonio de Hoyos y Vinent, que nos presenta, según Martín Rodríguez, "unas ficciones ambiguas y complejas que dan idea de su maestría como cultivador de la ficción fantástica, pese a lo tradicional de sus temas" (2015: 24-25). Cruz Casado, quien vincula los relatos fantásticos de Hoyos y Vinent con el Modernismo, alude a "la utilización de temas sobrenaturales" (1987: 403) en sus cuentos en los que encontramos una "referencia al mundo irracional y sus pobladores, con toda su secuela de fuerzas oscuras y misteriosas" (1987: 403). En cuanto a los personajes vinculados a la locura, Cruz Casado considera que muchos de ellos "sufren enfermedades bíblicas" (1987: 403-404), mientras que otros "son víctimas de extraños doctores con poderes hipnóticos, que incluso pueden arrancar los ojos de sus pacientes" (1987: 404). En cuanto al origen literario, para Cruz Casado, se

\footnotetext{
${ }^{6}$ Tzvetan Todorov (1970): Introduction à la littérature fantastique. París, Edition du Seuil. Trad. esp.: (1972): Introducción a la literatura fantástica. Buenos Aires, Tiempo Contemporáneo.
} 
encuentra en escritores como Villiers, Jean Lorrain o Marcel Schwob, "aunque en el fondo late el espíritu de Poe y su obsesión por lo misterioso y lo lúgubre” (1987: 404). Estos relatos están, en su mayoría, narrados en primera persona por parte de un perturbado mental, testigo de una transgresión que tiene lugar en un marco espaciotemporal propicio para su irrupción, que recurre a unos elementos externos para confundir y atemorizar al personaje principal, y que no se aferra a la locura para tener una explicación razonable, sino que deja al lector en un estado de incertidumbre. Esta es, en líneas generales, la estructura global de los cuentos que vamos a estudiar.

Como es habitual en este tipo de relatos, el narrador, en primera persona, revela desde el principio su locura o su perturbación mental. Es una forma de narrar que se ajusta a la teoría de Todorov (1970), quien considera que lo fantástico debe estar narrado en primera persona por ser esta la forma más directa para penetrar en el universo fantástico, y es lo que hace que el lector se identifique con el personaje. Así, "la narración en primera persona es la que mejor contribuye a la creación del fenómeno fantástico" (Ezama, 1994: 80). La técnica narrativa que más se adapta en este tipo de relatos es el monólogo que es "la forma más frecuente de la narración en primera persona, y también la más efectiva de cara al logro del efecto fantástico, porque en ella nos situamos en el centro mismo de la conciencia enajenada del personaje, sin intermediarios" (Ezama, 1994: 80). Así, en "Una noche bajo el terror" y en "Un amor de ultratumba", el anuncio de la locura por parte del narrador-personaje es explícito, aunque la forma es distinta. En el primer cuento no se pronuncia la palabra "locura" sino la palabra "neurastenia". 7 Además, el autor hace alusión a su locura a través de la mención de un espacio que es el sanatorio: "Retenido en la ciudad por la guerra, que no me había permitido proseguir mi viaje hacia el Sanatorio suizo, donde mis nervios, sacudidos por la neurastenia habían de encontrar reposo" (1916: 10) ${ }^{8}$. Cabe mencionar que el sanatorio o el manicomio están muy presentes en los cuentos fantásticos españoles a partir de finales del siglo XIX: Barella (1994) habla de "nueva institución del manicomio", mientras que Ezama considera que "esta casuística en relación con la enfermedad mental se dibuja sobre el telón de fondo de una institución manicomial que no pasa de ser un marco en el que se sitúa el personaje" (1994: 80). Aun así, contrariamente a los cuentos mencionados por Ezama, los de Hoyos no están ambientados en los manicomios. En el segundo cuento el narrador admite que sufre una locura, resultado de una obsesión o de una fobia que le llevó a aislarse de todo el mundo al estar convencido de que la gente le persigue para hacerse con su fortuna: "Mi salud rota, deshecha, bamboleándose como un barco desmantelado por los mares de la locura, mi fortuna enorme, que no me servía sino para vivir en un escepticismo amargo, lleno de sarcasmos, viendo en los demás una perpetua persecución de mis millones, todo contribuía a mi aislamiento (237).

En "Un cadáver sin identificar", la declaración de la locura del narrador-personaje es menos directa, hay una insinuación sobre este estado: "Y, sin embargo, esos raros personajes hechos de trapos, de claro obscuro y de silencio, nos han llevado de la mano hasta las fronteras de la locura" (55). En este caso, no hay una declaración manifiesta sobre la locura

\footnotetext{
${ }^{7}$ Hoyos y Vinent suele usar el término neurastenia y neurasténico. De hecho, escribió una novela titulada Las memorias de un neurasténico (1910), luego seleccionó unos de sus pasajes y los incluyó en el libro de cuentos Del huerto del pecado (1919).

${ }^{8}$ En nuestro análisis nos hemos basados en la edición del año 1916 de Los cascabeles de Madama Locura.
} 
del protagonista, tampoco está claro si se refiere a la locura en su sentido propio o en su sentido figurado. No se nos olvide destacar que la fiabilidad de estos cuentos, "que se presentan desde la conciencia enajenada del personaje, sin mediación de un narrador, y sin moraleja final" (Ezama, 1994: 80), está puesta en duda por varios críticos porque, según ellos, son narraciones que implican al receptor en un relato ambiguo, "de cuya veracidad se puede dudar, ya que la historia se nos ofrece desde la perspectiva de un narrador alucinado, y por lo tanto, poco fiable" (Ezama, 1994: 80).

El caso de "Una aventura de amor" es distinto, puesto que no hay coincidencia entre el narrador y el protagonista, lo que hace que se narre en tercera persona, "por lo que el cuento se construye en forma de diálogo, en que el último convierte al primero en su confidente, siempre incrédulo ante las fantasías del enajenado" (Ezama, 1994: 80). Hemos de señalar que el uso de la tercera persona, según críticos como Vax ${ }^{9}$ y Caillois, ${ }^{10}$ no tiene por qué reducir el efecto fantástico del relato: no es imprescindible que la narración se presente en primera persona por no considerar necesario un narrador específico. En el cuento de Hoyos, los síntomas de locura de Lorenzo Torreón se dan a través de la descripción que hace el narrador de su rostro, y a través de su comportamiento que es propio de un perturbado mental, aunque no se dice en ningún momento que sufra algún tipo de alteración psíquica:

Tenía, realmente, así, el rostro muy pálido, ajado y verdeante por la noche de juerga; los ojos mortecinos en el fondo de las violáceas ojeras; los labios descoloridos, caídos en las comisuras; los cabellos ocultos por el negro casquete, y el cuerpo fofo, blando, desarticulado, bajo el blanco atavío de amante de la Luna, el aspecto de uno de esos trágicos pierrots, que ríen ante una botella de champagne, sellados por el beso inexorable de la pálida. Inquietante su aspecto, bajo los amplios pliegues del traje de raso blanco, sus gestos eran a la vez rígidos y fofos, como los de esas marionetas abandonadas en la embocadura de los guignols. (23-24)

El narrador que, más adelante, presenta a Lorenzo como un hombre "nervioso, turbado, con mal humor" (27), pretende hacer que el lector deduzca su locura a través de un tipo de descripción que, según Ezama, corresponde al arquetipo del protagonista de los cuentos de locos, y en cuya apariencia física "hay algo extraño que se suele manifestarse en los ojos, en la risa incontratable, los gestos nerviosos o la abstracción" (1994: 80). En este aspecto, Comellas habla de la relación estrecha entre estos síntomas y el decadentismo, que está muy presente en la narrativa y pensamiento de Hoyos y Vinent, siendo uno de los máximos representantes de la literatura decadentista española ${ }^{11}$ :

Desequilibrio, tensión nerviosa y melancolía se explican en la teoría de la decadencia por el sentimiento de fracaso de toda la tradición occidental científica y filosófica que se vivió en Europa con la crisis del positivismo, al comprobar que tras haber destruido toda posibilidad de certeza, aquella tradición concluía sus afanes destructivos sin proponer una solución al hombre. (2001: 74)

\footnotetext{
${ }^{9}$ Louis Vax (1960): Arte y literatura fantásticas. Trad. Juan Merino. Buenos Aires, Editorial Universitaria de Buenos Aires [1965].

${ }^{10}$ Roger Caillois (1966): Imágenes, imágenes... (sobre los poderes de la imaginación). Trad. Dolores Sierra y Néstor Sánchez. Barcelona, Edhasa [1970].

${ }^{11}$ La relación entre el Decadentismo y el Modernismo es estrecha. En España, muchos escritores modernistas se dejaron llevar por esta nueva tendencia estético-literaria que ya había aparecido en Europa. Nos referimos a figuras como Valle-Inclán, Isaac Muñoz, Álvaro Retana, Emilio Carrere y el propio Hoyos y Vinent.
} 
En algunas ocasiones, y a pesar de que el narrador admita su locura, se resiste a relacionarla con la trasgresión. Esta forma de negación de la locura no hace más que confirmarla. Se trata de una técnica que los escritores españoles del siglo XIX y de principios del siglo XX heredaron de Poe y, más tarde, de Maupassant. En este aspecto, Roas considera que "la defensa de la cordura fue recurso habitual en la narrativa fantástica del siglo XIX, con el que se generaba una atmósfera de misterio e incertidumbre, a la vez que se involucraba al lector en la búsqueda (inútil) de una explicación racional de los hechos" (2011: 161). De allí, algunos de los enajenados "afirman insistentemente la veracidad de su historia, y declaran no estar locos" (Ezama, 1994: 80). Siguiendo esta línea, es difícil determinar, en muchas ocasiones, el grado de perturbación mental del protagonista, "de modo que el lector difícilmente puede estar seguro de la veracidad de lo contado" (Casas, 2008: 366). Así, en "Una noche bajo el terror", el protagonista quiere convencerse a sí mismo de que el fenómeno inexplicable que ha presenciado no es solamente producto de su perturbación mental: "Inútil que me repitiese una y otra vez que con aquellas correrías no hacía sino exacerbar mi neurastenia, inútil que lo achacase todo a fantasmagorías de mis nervios sobreexcitados" (15). Lo mismo decimos de "Un cadáver sin identificar", donde el personaje principal anuncia que sus "nervios debían hallarse distendidos" (56), lo que descartaría cualquier vínculo entre su estado mental y la irrupción del fenómeno fantástico.

En cuanto al marco espaciotemporal que acoge esta combinación entre lo fantástico y la locura, es, como hemos mencionado, cotidiano y próximo al lector, en su intento de hacer más creíble y más verosímil la historia. El tiempo de la historia de esos relatos es contemporáneo a ellos, y el momento del día más frecuente es la noche, porque la oscuridad, como apunta Estrada Herrero, "proyecta sobre las cosas un carácter de vaguedad, incertidumbre y confusión" (1988: 647), suscitando un sentimiento de terror hacia lo desconocido, que es muy propio de los relatos fantásticos. Los cuentos de Hoyos y Vinent no van a ser la excepción: Alfonso García alude a la inclinación de nuestro escritor por este momento del día, muy significativo para él:

La noche es, pues, en principio, el marco adecuado para abandonarse a los excesos y transgredir los límites de lo permitido, respondiendo a las necesidades más ocultas del alma; por lo mismo es también reveladora cruel de la realidad, que descubre la mentira y la hipocresía que en la claridad diurna son imposibles de apreciar. Finalmente, es el ámbito que, con sus juegos de luces y sombras, proporciona una nueva captación del entorno, que adquiere distintos matices, evocadores de mundos oníricos. (1998: 132)

En "Una noche bajo el terror", como bien lo indica el título, la noche es el marco temporal en el que se produce el fenómeno fantástico, es el momento ideal para buscar aventuras misteriosas: "Vagaba yo de noche, en busca de lo imprevisto" (11). Lo mismo podemos decir de "Una aventura de amor", donde lo sobrenatural también se produce por la noche: "El reloj del convento cantó en la noche doce campanadas" (29); mientras que en "Un cadáver sin identificar", la noche se presenta como el momento del día en el que aparecen los fantasmas: "Yo no sé si por vicio imaginativo, por fatalidad, o por raro azar, para mí la noche ha estado siempre poblada de fantasmas" (55). La noche es también el momento idóneo para buscar la aventura manifestada en "la colección de perversidades que nacen del deseo de distraer el tedio, convertido en motor de la acción en cuanto la dirige a nuevas experiencias" (Comellas, 2001: 77). La aventura, como afirma Comellas, es el resultado de la desolación del 
ser humano que se refleja en el decadentismo, y que conduce a la literatura del Mal que, como en Baudelaire, "invita a la búsqueda de novedades que hagan más atractiva una existencia sin sentido (2001: 77).

En cambio, "Un amor de ultratumba" es el único cuento en el que la transgresión no se produce por la noche sino a las dos de la tarde, lo que muestra que lo fantástico puede producirse en cualquier momento del día. En cuanto al espacio, en los cuatro cuentos, los acontecimientos se desarrollan en la ciudad, y especialmente en Madrid: un espacio real y cotidiano. Hay que decir que, igual que el marco temporal, uno de los grandes cambios que sufrió el cuento fantástico español de finales del siglo XIX y principios del siglo XX fue, como apunta Ana Casas, alejarse de la concepción romántica a través del abandono paulatino de lo legendario, y sustituirlo por unos ambientes cotidianos para el desarrollo de la acción, "asumiendo un mayor realismo, extremando los elementos verosimilizadores, acercándose, en definitiva, cada vez más al mundo del lector" (2008: 358). Esta explotación de los espacios cotidianos y de los ámbitos conocidos por el lector se debe a un ímpetu de "hacer más creíbles, y, a la vez, más impactantes los hechos relatados” (Roas, 2011b: 20). Así, las historias se desarrollan en unos espacios comunes como el palacio, la habitación de hotel o el cementerio.

En algunas ocasiones asistimos a unas descripciones de ambientes propios de la literatura gótica, que al mismo tiempo no desentonan con la línea general de los cuentos, sobre todo porque los inicios de los temas de locura se encuentran en las historias góticas donde los desórdenes mentales y nerviosos se convirtieron en tema ideal "porque las ilusiones de los locos a menudo se parecen a las esencias tradicionales y supersticiones" (Bravo, 2013: 55), y es lo que hace que el poder psicótico seduzca al escritor gótico. Es oportuno señalar que Hoyo y Vinent, como otros escritores modernistas, cultivan lo gótico a partir de la nueva forma que le dio Poe a la hora de tratar lo macabro (Roas, 2011); por eso, "el gusto por lo lúgubre y escabroso es muy perceptible en autores modernistas" (2011: 158) como Hoyos y Vinent, "quien incluso menciona el nombre de Poe en varios de sus relatos para destacar la dimensión macabra que se va a narrar” (2011: 158). Así, los elementos góticos en los cuentos de Hoyos y Vinent sirven para crear una atmósfera propicia a la locura de los personajes, y es lo que percibimos en "Una noche bajo el terror", en el que el autor da al palacio un toque lúgubre y atemorizador, que intensifica aún más la perturbación del narrador-protagonista: "El fondo era inquietante: techo abovedado, paredes ennegrecidas por la humedad, y en torno a ellas viejas banquetas de laca blanca, con almohadones de terciopelo azul porcelana. La luz de un velón, pendiente del techo, hacía aún más temeroso el ambiente" (13). En "Una aventura de amor", la descripción de un ambiente lúgubre prepara al lector para la producción de un fenómeno siniestro: "Al abrirse la puerta de la escalera, una corriente glacial, impregnada de ese escalofriante olor a moho y a humedad que tienen los recintos largos tiempos cerrados, olor de mansión abandonada, de convento en ruinas y de sepultura, llegó hacia él, y la gota de mercurio volvió a resbalar por su espalda" (26). En "Un cadáver sin identificar", el hotel adquiere este carácter atemorizador: "Era el albergue un viejo edificio provinciano, destartaladote y grandísimo, con largos pasillos que formaban laberintos, escaleras tortuosas y cuartos de alto techo y paredes enyesadas" (58).

Aunque el fenómeno fantástico en estos cuentos es interior y se asocia a la imaginación del personaje, hay un elemento exterior que se encarga de atemorizar al 
protagonista, y que está estrechamente vinculado a lo sobrenatural. ${ }^{12}$ Este elemento, que es un personaje, es producto de la imaginación del protagonista, y se asocia con el elemento interior para producir la trasgresión o este mismo la produce. En este sentido, Ana Casas habla de una combinación entre la amenaza interior y exterior "con la posibilidad de que nuestra voluntad pueda ser controlada por otro ser” (2008: 364). Uno de estos personajes que más protagonismo tienen en los relatos de Hoyos es la mujer fatal y siniestra, cuya belleza y capacidad de dominio hace que sea un peligro para el hombre, inspirándole a la vez fascinación y terror, como apunta Ana Casas en un estudio sobre la mujer y la sexualidad en el cuento del fin de siglo; es el resultado de una coexistencia entre "la atracción y el miedo que la unión sexual inspira, tal y como manda una sociedad que, si bien siente fascinación por el erotismo y sus formas, somete «las bajas pasiones» a férreos convencionalismos" (Casas, 2010b: 2). Por eso, Cruz Casado habla de "hembras voraces que dominan el amante" (1987: 402-403) en muchos relatos de Hoyos y Vinent. En "Una noche bajo el terror", una mujer es la que se encarga de sembrar el terror y el pánico en el corazón del protagonista, una mujer siniestra al más puro estilo hoffmaniano encontrada en un palacio: “¡Aquella mujer! Prolongación caricaturesca de una vida de frivolidad, figura de un viejo de feria, rico en muñecos de cera" (13). El autor describe detalladamente aquella mujer que va a ser la fuente de lo fantástico terrorífico:

Alta, esquelética, envuelta en las galas del siglo XVIII, unas galas de museo, marchitas y desvaídas, el busto encorvado, muy estrecho de hombros, envuelto en un chal de tejido de plata, aún más viejo y desvaído que el resto, destacábase la cabeza con todo el espanto de esos trofeos que pasearon los sans-culotte en la punta de sus picas. Demacrado, cadavérico, la piel como viejo pergamino se arrugaba en torno de la boca sin dientes y de los ojos hundidos, negros y relucientes como carbunclos, mientras la nariz ganchuda parodiaba el pico de un ave de rapiña en el rostro atroz. Y sobre aquella cara de vieja muerta, los labios pintados de bermellón y dos cínicos rosetones, ponían una máscara irónica de coqueta casquivana. Completaba la figura altísima peluca blanca, coronada de marchitas rosas de trapo. (14)

Así, la perturbación mental del protagonista, debido a la aparición en escena de esta mujer, hace que una sensación de inquietud le acompañe constantemente y que vaya aumentando al encontrarse con la mujer de aspecto inquietante en el palacio: "Alucinado, hipnotizado por el horror y la curiosidad" (14). En "Una aventura de amor", lo fantásticoterrorífico proviene también de una mujer: "Debería ser muy rubia, porque a través del velo que envolvía su cabeza, el pelo amarilleaba, dando la extraña sensación de un casco de marfil o un cráneo pelado (30). Es oportuno recordar que la presencia de la mujer ligada a las perversiones patológicas en los relatos de Hoyos y Vinent es fruto de su vinculación al naturalismo, lo que hizo que se considerara un novelista erótico, además de sus tendencias modernistas y decadentistas. Por eso, obras como El monstruo, El pecado de la noche o El

\footnotetext{
${ }^{12}$ En este tipo de relatos, la conexión entre lo fantástico y la locura crea un sentimiento de miedo anterior a la producción del fenómeno fantástico. Es oportuno anotar que el miedo, en sus diferentes manifestaciones, es un elemento primordial dentro de lo fantástico, y es una condición necesaria para su creación, lo que hace que el relato fantástico provoque, necesariamente, inquietud en el lector. Esta inquietud es una reacción por parte de los personajes y por parte del lector "ante la idea de que lo irreal pueda irrumpir en lo real" (Roas, 2001: 30), una reacción que les lleva a dudar de su propia realidad. Así, cualquier sentimiento de terror, de miedo o de angustia trasladado a los personajes o al lector es un sentimiento que nace de una trasgresión de las leyes físicas que ordenan nuestra concepción de lo real, tal como apunta Roas (2001) coincidiendo con críticos como Lovecraft, Caillois, Bellemin Noël, Bessière, Penzoldt o Jackson.
} 
caso clínico, entre otras, dejan ver el gran protagonismo que Hoyos concede a este tipo de personajes. Hibbs-Lissorgues alude a esta omnipresencia en las obras del escritor madrileño:

La obra de Vinent, desmesurada y expresionista, ofrece una descripción compleja del peligroso deseo femenino. Un deseo que, en sus manifestaciones perversas, se despliega generalmente en un ambiente maléfico. Novelas y cuentos de este autor quien, después de un periodo de olvido, parece atraer de nuevo la atención de la crítica, están impregnados, como la obra de otros escritores del naturalismo radical español (Alejandro Sawa, Eduardo López Bago, Remigio Vega Armentero), de las tesis de antropólogos y criminalistas de finales del siglo XIX y principios del siglo XX: atavismo, locura, prostitución y crimen son la consecuencia de las alteraciones regresivas de la naturaleza. Si estas anomalías son escrupulosamente analizadas y clasificadas dentro de una finalidad de profilaxis social, son también el pretexto para una estética de lo excesivo. La influencia de la antropología lambrosiana y del determinismo biológico, que tratan de cernir las enfermedades del cuerpo social, descorchan sobre una iconografía de lo anormal del exceso: mundo de los prostíbulos de las ciudades, ninfomanía y degeneración física, sexualidad mórbida huella de pulsiones sádicas, crimen. ${ }^{13}$ (2001, traducción mía)

En este aspecto, Comellas alude a Cansinos-Asséns quien, en su clasificación de los escritores eróticos, considera que Hoyos pertenece a lo que él denomina "amor monstruoso". Por eso, el tema sexual en sus relatos "está asociado a lo irracional, a lo horroroso, al miedo, al crimen y la disolución" (Comellas, 2001: 61). Se trata, pues, de un "erotismo enfermizo y perverso" (2001: 61), que "sirve de escenario [para] una estética de lo lúgubre, lo marginal, lo brutal y lo miserable" (2001: 61). En este aspecto, Phillips-López vincula el Modernismo con "la parafernalia del nuevo horror (psicologizante) moderno" (2003: 43). En "Un cadáver sin identificar", este tipo de personaje se presenta de una forma menos explícita: no se habla de un personaje en concreto, sino de unos personajes que llevan a otros al borde de la locura después de tener con ellos "escalofriantes encuentros en el silencio sonoro de la noche" (55). Igual que el cuento anterior, la angustia se apodera del protagonista antes de la producción del fenómeno fantástico: "una leve sensación de temor me sobrecogía todas las noches al cruzarlos" (58).

Con la producción de la transgresión, el miedo se intensifica y se mezcla con un estado de perplejidad. De hecho, para que el efecto fantástico se produzca es imprescindible que haya un sentimiento de amenaza que se apodere de nosotros después de haber trastornado nuestra concepción de la realidad. El trastorno es el resultado de la entrada en escena de un fenómeno inexplicable (inadmisible), que está estrechamente vinculado a lo imposible, que al mismo tiempo "supone una alteración del mundo familiar del lector" (Roas, 2006: 99). Ante este suceso inexplicable, el lector siente miedo o temor, consecuencia de una "irreductibilidad" al sentirse incapaz de concebir o de aceptar "la coexistencia de lo posible

\footnotetext{
13 “L'œuvre de Vinent, démesurée et expressionniste, offre une description complexe du «dangereux» désir féminin. Un désir qui, dans ses manifestations perverses, se déploie généralement dans un environnement maléfique. Romans et nouvelles de cet auteur qui, après une période d'oubli, semble attirer à nouveau l'attention de la critique, sont imprégnés comme l'œuvre d'autres écrivains du naturalisme radical espagnol (Alejandro Sawa, Eduardo López Bago, Remigio Vega Armentero) des thèses d'anthropologues et criminalistes de la fin du XIXe et du début du XXe siècle : atavisme, folie, prostitution et crime sont la conséquence des altérations régressives de la nature. Si ces anomalies sont scrupuleusement analysées et classées dans une finalité de prophylaxie sociale, elles sont aussi le prétexte à une esthétique de l'outrance. L'influence de l'anthropologie lombrosienne et du déterminisme biologique qui tentent de cerner les maladies du corps social débouchent sur une iconographie de l'anormal et de l'excès : monde prostibulaire des villes, nymphomanie et dégénérescence physique, sexualité morbide empreinte de pulsions sadiques, crime".
} 
con un imposible o, lo que es lo mismo, de admitir la ausencia de explicación —natural o sobrenatural codificada - para el suceso que se opone a todas las formas de legalidad comunitariamente aceptadas" (Roas, 2006: 113). Así, la base de lo inexplicable, de lo imposible, es la transgresión.

En "Una noche bajo el terror", el aspecto inquietante de la mujer supone la irrupción de un fenómeno inexplicable, cuya producción aumenta la sensación de amenaza en el protagonista: "Confieso que sentí un escalofrío recorrerme las espalda" (18), y que se convierte en un auténtico terror: "Sin poder remediar me aproximé, y mis cabellos se erizaron, mientras se helaban mis espaldas y mis piernas temblaban. ¡Allí, en el fondo de la redoma, se veía la truncada cabeza de Marie Antoinette!" (18). La transgresión culmina cuando resulta que el narrador vivió una reproducción del pasado a través de sus diferentes episodios (dentro del museo):

Y se ofreció a mis ojos, grotesca, espantosa y alucinante en el claro-oscuro de la inmensa estancia. Las sayas pomposas, marchitas y descoloridas se desbordaban del aparato de muerte; las manos sarmentosas se crispaban de horror mientras, sostenida por un cuello rugoso y descarnado, la cabeza, coronada por inmensa peluca oscilaba sobre el cesto. Maquinalmente tendí la mano y apreté el resorte. Brilló un relámpago azulado, resbaló silbando la cuchilla, y la cabeza cayó tronchada. (19-20)

Esta reproducción del pasado corresponde a "la creencia en la transmigración de las almas” (Ezama, 1994: 80), por lo que podríamos relacionar este cuento con los casos supranormales que están entre la locura y la parapsicología según la clasificación de G. Ponnau en la que se basa Ezama. En "Una aventura de amor", la angustia de Lorenzo cede lugar al miedo en forma de pánico cuando Lorenzo presencia la irrupción de un fenómeno sobrenatural que amenaza su integridad física: Lorenzo siente un doble miedo al ver puestas en duda sus códigos de la realidad por encontrarse ante un fantasma, y al sentir una amenaza real contra su vida: "Y como ella, sin hacerle caso, siguiera arrastrándole, enloquecido, ciego de pánico, sacó el cuchillito y asestóla una puñalada. La acerada lámina chocó contra un hueso y el fantasma desplomóse a tierra" (33). Lorenzo, como acabamos de ver, apuñala al fantasma: se trata, como apunta Ana Casas, de un acto que muestra que "lo fantástico sirve muchas veces para descargar la responsabilidad de un acto «censurable» en un ente sobrenatural" (2008: 365). Por otra parte, el crimen cometido por Lorenzo confirma la relación estrecha entre la locura y el deseo sexual dentro de lo fantástico, y entre la locura o la perturbación mental y el deseo carnal, por lo que abundan en este tipo de relatos "las puestas en escena perturbadoras del deseo y de la sexualidad" (Phillips-López, 2003: 43). Ana Casas alude a esta conexión, que "permite reflexionar sobre determinados aspectos de la mente humana: los meandros de la personalidad, la pulsión de violencia y también sobre el deseo sexual” (2008: 367). Define de esta forma la conexión entre la locura y el deseo sexual en los relatos fantásticos de Hoyos y Vinent:

Antonio de Hoyos y Vinent es otro de los autores que explora, aunque no siempre con acierto, la conexión entre lo fantástico, la locura y el erotismo: así, "Una hora de amor" (El pecado y la noche), donde una prostituta se ve asaltada por un vampiro en horas bajas o por un perturbado mental, pues la cosa no queda clara; pero sobre todo "El hombre de la muñeca extraña", relato que empieza siendo fantástico (tiene lugar una escena en la que cobran vida los muñecos de cera de un museo) para acabar abandonando este aspecto a favor de otros de carácter no sobrenatural. (2008: 367) 
En este contexto, Hoyos y Vinent, como otros escritores españoles, lleva el sexo al terreno de lo no-convencional haciendo que en sus textos cobren protagonismo algunas prácticas patológicas, por lo que la lujuria pasa al terreno de lo enfermizo, como apunta Ana Casas (2010b). El deseo sexual vinculado a la mujer, ${ }^{14}$ a la vez exuberante y peligrosa, no solo se encuentra en estos relatos de Hoyos y Vinent, sino en otros como "El señor cadáver y la señorita vampiro", en el que el autor retrata la figura de "la hembra de apetito insaciable, tentadora ávida de simiente y en busca perpetua del macho" (Casas, 2010b). En "Un cadáver sin identificar", los temores del protagonista se confirman con la transgresión a través de la aparición de un cadáver en descomposición en la habitación del narrador. En este aspecto, Martín Rodríguez alude al relato de Maupassant, "El Horla" que, según él, "pudo inspirar a Hoyos y Vinent la idea del ser que impone su presencia fantasmal al protagonista propenso al miedo, en el espacio privado de su casa" (2015: 21). Este hecho hace que el cuento pueda considerarse fantástico "en la medida en que logra expresar la presencia del fantasma gracias a sus descripciones morbosamente detalladas, que lo ofrecen en toda su materialidad repugnante" (Martín Rodríguez, 2015: 22). No se trata de un cadáver cualquiera sino del hombre que desapareció hace varios días, y que la policía no pudo encontrar:

Era un cuerpo de hombre, o mejor dicho un esqueleto de hombre todo desnudo y rematándolo la cabeza del viejo, la cabeza alucinante que hacía ocho días habían publicado todos los periódicos [...] una cabeza amarillenta, tumefacta, manchada de redondeles amoratados, los labios violáceos entreabiertos y los ojos cerrados, es decir, cerrados no por debajo de uno de los párpados asomaba un repugnante y tenebroso gusano verde. (59)

En "Un amor de ultratumba", la transgresión siembra el terror en el corazón del protagonista al ver que su difunta amada recobró vida:

De pronto mis cabellos se erizaron y sentí un escalofrío de espanto. ¡Aquella mano se movía! ¡Por algunos instantes la mano se agitó! ¡Me llamaba! No había duda. [...] Pero yo ahora sentía que algo anormal, algo que saliendo de los límites de las cosas lógicas penetraba en el mundo misterioso del problema, sucedía. Una luminosidad extraña fingía sobre el esqueleto la grácil figura de la muerte, una figura traslúcida, inconsistente que yo sólo veía. Y la muerta me hablaba. (239)

La transgresión, junto al terror, provoca casi siempre una situación de incertidumbre: no se sabe hasta qué punto es producto de la imaginación del protagonista. La duda entra en escena: el protagonista no sabe si está loco o cuerdo, si lo ocurrido fue un sueño o la realidad. De esta forma podemos incluir estos fenómenos dentro de los relatos de extrañeza psíquica y, más precisamente, los relacionados con las alucinaciones, según la clasificación que sigue Ezama; en este aspecto, estas alucinaciones están situadas "entre la razón y la locura" (1994: 79). En "Una noche bajo el terror", el narrador-protagonista revela su duda de esta forma: "Petrificado, meciéndome entre la razón y la locura, me preguntaba yo si vivía realmente o si vagaba por los terrenos de la pesadilla" (14). En "Una aventura de amor", la duda y la incertidumbre de Lorenzo acerca del fenómeno siniestro salen a la luz a través de una serie de preguntas: “¿Quién sería la incógnita? ¿Una enamorada discreta? ¿Una bromista? ¿Una encerrona con vistas al chantage?” (27); ¿Sueño? ¿Realidad? ¿Imágenes de una terrible

\footnotetext{
${ }^{14}$ Véase José Antonio Sanz Ramírez (2010): Antonio de Hoyos y Vinent: Genealogía y elogio de la pasión. Madrid, Universidad Complutense de Madrid. Tesis Doctoral.
} 
pesadilla o hechos ciertos?” (33). Esta alusión al sueño nos lleva a la segunda categoría de los cuentos fantásticos, la de "Osmisis y la psicopatología y lo fantástico, y, especialmente, los relacionados con los sueños (Ezama, 1994). La duda de Lorenzo se intensifica al final del relato: "aquello que no sabía si era realidad o alucinación" (33). En "Un amor de ultratumba", el desconcierto del protagonista se trasmite también a través de unas preguntas: "Dos lágrimas — ¿eran lágrimas o gusanos? — se deslizaron lentos por los pómulos" (240); "Sus pupilas verdes — ¿pupilas o gusanos? - brillaban en la semipenumbra” (240).

Hasta aquí todo indica que el fenómeno inexplicable ha sido el resultado de la imaginación del protagonista, producto de su mente enferma y perturbada. Pero de ser así, el fenómeno fantástico no tiene razón de existir, ya que tendría una explicación racional. Por eso, asistimos en estos cuentos a un final abierto, en el que se da la razón al protagonista respecto a los fenómenos que presencia, descartando por completo que fuera fruto de su imaginación. Este tipo de sucesos intensifica el fenómeno fantástico y, lejos de resolver las dudas del lector, las aumenta. La incertidumbre es la esencia de lo fantástico, por eso Todorov afirma que "Tanto la incredulidad total como la fe absoluta nos llevarían fuera de lo fantástico; lo que le da vida es la vacilación" (2001: 54). Belevan ${ }^{15}$ establece, igual que Todorov, la vacilación como el elemento que define lo fantástico; así, cuando se pierde la vacilación, se pierde lo fantástico. En "Una noche de terror", una noticia en el periódico confirma lo ocurrido con el narrador la noche anterior, e intensifica la duda del lector sobre si lo que pasó fue verdad o es producto de la imaginación del narrador:

Una vulgar tragedia, uno de esos dramas que tienen, sin embargo, todo el espanto de una narración de Poe, ha tenido lugar anoche en el antiguo palacio del famoso Cardenal de Rohan [...]. La primera noche nada de anormal se dio, y tan solo los empleados que hacen la limpieza encontraron un ligero desorden en el vestuario antiguo que guarda el museo; pero hoy, al entrar, hallaron todas las puertas abiertas de par en par, y al llegar armados al salón de la guillotina, un cuadro espantoso se ofreció a sus ojos. Tendida sobre el terrible aparato, vestida de fantásticas galas, ajadas y polvorientas, yacía la anciana ¡idecapitada!! Un hilo de sangre... $(20-21)$

Al final, un dato confirma que el narrador estuvo en el lugar del crimen, lo que intensifica aún más la duda y el desconcierto del lector: “iiSobre uno de los puños de mi camisa, tirada en una silla, brillaba como un rubí maldito una gota de sangre!!" (21). En "Una aventura de amor", las palabras de uno de los presentes en el baile aumenta la duda y el desconcierto de Lorenzo y del lector, lo que nos introduce en lo puramente fantástico, puesto que la vacilación del lector es, según Todorov, "la primera condición de lo fantástico" (2011: 54). Así, “¡El cuerpo de una mujer que dejan en el Depósito de cadáveres y por cierto con las sortijas puestas para que pueda ser reconocida, y que aparece con una puñalada en el pecho, sin que nadie haya entrado allí!" (34). En "Un cadáver sin identificar", la criada es la que da la noticia al protagonista confirmando, así, que todo lo que había presenciado era real: “¡Han encontrado el cadáver!... Estaba todo desnudo, tirado en la cueva de una casita cerca de Madrid” (60). El desconcierto del narrador crece al final del cuento: “¡Las maderas de la ventana estaban abiertas, y en la otra cama se veían las huellas de un cuerpo que había descansado allí!" (60). Estos hechos dan la razón a los que defienden la teoría de que "las

\footnotetext{
${ }^{15}$ Harry Belevan (1976): Teoría de lo fantástico. Apuntes para una dinámica de la literatura de expresión fantástica. Barcelona, Anagrama.
} 
imaginaciones de los autores de literatura fantástica no son alucinaciones ni cosas de locos, porque en la vida real se da esa clase de sucesos inexplicables" (Martin Rodríguez, 2015: 24). En "Un amor de ultratumba", el final es incomprensible: no hay ningún hecho que confirme o desmienta lo ocurrido con el protagonista, cuya difunta amada recobró vida y le acompañó a su casa. No tenemos, como en los cuentos anteriores, un dato que contraste con el fenómeno transgresor, y que aumente la duda del lector sobre la veracidad de lo ocurrido, aunque tampoco nos revela que todo fue producto de un sueño y de una alucinación: "Me faltó pie y caí en un abismo, helado, lóbrego, sin fin..." (241). Se trata, como afirma Martín Rodríguez, de un final abrupto que impide definir el domicilio del protagonista "como espacio real o como la descripción clínica de un desvanecimiento, sin descartar otras posibilidades que se confían sugestivamente a la imaginación de los lectores" (2015: 24).

En definitiva, el estudio de los cuentos fantásticos de Hoyos y Vinent, y cuyo eje central es la locura, nos reveló que el autor siguió la línea de lo fantástico interior que habían trazado los grandes maestros de la literatura fantástica dentro y fuera de España, dejando su propia huella que le distingue de sus coetáneos. Por eso, el tema de la locura es tratado desde varias perspectivas: la historia no se narra siempre en primera persona; las historias, a pesar de tratar el tema de la locura, no están ambientadas en sanatorios y manicomios; la noche no es el único momento del día en el que se produce la transgresión; el espacio es cotidiano con un toque gótico; el género femenino es fundamental para crear el fenómeno a la vez sobrenatural y terrorífico; la locura del personaje principal es cuestionada y está puesta en duda; el final abierto aumenta el desconcierto del lector sobre el estado psíquico del personaje principal y sobre la veracidad del fenómeno sobrenatural. Sin olvidar la presencia de rasgos que dejan en evidencia las influencias literarias en las obras de nuestro escritor, encontramos toques decadentistas, naturalistas y modernista. En definitiva, son muchos los recursos que maneja Hoyos y Vinent en sus relatos fantásticos, lo que hace de él un escritor peculiar y diferente del resto de sus coetáneos, entre ellos, los cultivadores del género fantástico, con "una narrativa singular, heredada de la cultivada en nuestras fronteras" (Alfonso García, 1998: 14). Cruz Casado explica esta peculiaridad de la literatura fantástica de Antonio de Hoyos y Vinent de la siguiente forma: "Los amores de ultratumba, los incubos, las ciudades sumergidas, y toda una larga secuela de elementos sobrenaturales, llenan los atractivos cuentos de Hoyos, mezclado todo ello con la lujuria, la locura y la muerte" (1987: 404).

\section{Bibliografía}

ALFONSO GARCÍA, Ma del Carmen (1998): Antonio de Hoyos y Vinent, una figura del decadentismos hispánico. Oviedo, Universidad de Oviedo, Departamento de Filología Hispánica.

BARELLA, Julia: “La literatura fantástica en España”, Anthropos, 154-155 (1994), 11-18.

BELEVAN, Harry (1976): Teoría de lo fantástico. Apuntes para una dinámica de la literatura de expresión fantástica. Barcelona, Anagrama.

CAILlOIS, Roger (1966): Imágenes, imágenes... (Sobre los poderes de la imaginación). Trads. Dolores Sierra y Néstor Sánchez. Barcelona: Edhasa [1970].

CASAS, Ana: (2008) "El cuento modernista español y lo fantástico". En Teresa LÓPEZ PELLISA y Fernando Ángel MORENO SERRANO (eds.): Ensayos sobre ciencia 
ficción y literatura fantástica: Actas del Primer Congreso Internacional de literatura fantástica y ciencia ficción 1. Madrid, Asociación Cultural Xatafi - Universidad Carlos III de Madrid, 358-378.

CASAS, Ana: "El cuento galante en 1900: del amor idealizado a los peligros de la carne", Lejana. Revista crítica de narrativa breve, 1 (2010a), 1-13.

CASAS, Ana: "Placeres prohibidos y transgresión moral: mujer y sexualidad en el cuento del fin del siglo", Espéculo. Revista de estudios literarios, Universidad Complutense de Madrid, 46 (2010b),

https://pendientedemigracion.ucm.es/info/especulo/numero46/placepro.html, 26/09/2016.

COMELLAS AGUIRREZÁBAL, Mercedes: "El novecentismo como encrucijada: Antonio de Hoyos y Vinent”, PHILOLOGIA HISPALENSIS, 15 (2001), 43-80.

CRUZ CASADO, Antonio (1987): "Modernismo y Parodia en la narrativa de Antonio de Hoyos y Vinent". En Guillermo CARNERO ARBAT (coord.): Actas del Congreso Internacional sobre el Modernismo español e hispanoamericano y sus raíces andaluzas y cordobesas. Córdoba, Diputación de Córdoba, 398-407.

ESTRADA HERRERO, David (1988): Estética. Barcelona, Editorial Herder.

EZAMA GIL, Ma de los Ángeles: "Cuentos de locos y literatura fantástica: aproximación a su historia entre 1868 y 1910”, Anthropos, 154-155 (1994), 77-82.

GONZÁleZ MIGUEL, $\mathrm{M}^{\mathrm{a}}$ de los Ángeles (2000): E.T.A. Hoffmann y E.A. Poe. Estudio comparado de su narrativa breve. Valladolid, Universidad de Valladolid.

HERRERO CECILIA, José (2000): Estética y pragmática del relato fantástico. Cuenca, Ediciones de Castilla-La Mancha.

HIBBS-LISSORGUES, Solange (2011): "L'obscur objet du désir : crimes de femme(s) dans l'oeuvre romanesque de Antonio Hoyos y Vinent (1844-1940)", Biblioteca Virtual de Miguel de Cervantes, http://www.cervantesvirtual.com/obra/lobscur-objet-du-desircrimes-de-femmes-dans-loeuvre-romanesque-de-antonio-hoyos-y-vinent-1844-1940/, 04/09/2016. Reproducción de Femmes criminelles et crimes de femmes en Espagne (XIX y XX siècles), Lasman Editeur, 2010, 145-163.

HOYOS Y VINENT, Antonio de (1916): Los cascabeles de Madama Locura. Madrid, Biblioteca Hispania.

MARTÍN RODRÍGUEZ, Mariano (2015): "Monstruos y fantasmas de la decadencia: Los cascabeles de Madama Locura, de Antonio de Hoyos y Vinent”. En Antonio de HOYOS Y VINENT: Los cascabeles de Madama Locura. Madrid, La Biblioteca del Laberinto, 7-33.

MOLINA PORRAS, Juan (2006): Cuentos fantásticos en la España del Realismo. Ed. Juan Molina Porras. Madrid, Cátedra.

PHILlIPS-LÓPEZ, Dolores (ed.) (2003): Cuentos fantásticos modernistas de Hispanoamérica. Madrid, Cátedra.

PONNAU, Gwenhael (1990): La Folie dans la littérature fantastique. París, Editions du CNRS.

ROAS, David (2001): "La amenaza de lo Fantástico". En David ROAS (ed.): Teorías de lo fantástico. Madrid, Lecturas, 7-44.

ROAS, David (2002): Hoffmann en España. Madrid, Biblioteca Nueva. 
ROAS, David: "Hacia una teoría del miedo y lo fantástico", Semiosis, II/3 (2006), 95-116.

ROAS, David (2011a): La sombra del cuervo. Edgar Allan Poe y la literatura fantástica española del siglo XIX. Madrid, Devenir Ensayo.

ROAS, David (2011b): Tras los límites de lo real. Una definición de lo fantástico. Madrid, Páginas de Espuma.

ROAS, David y Ana CASAS (eds.) (2008): La realidad oculta. Cuentos fantásticos españoles del siglo XX. Palencia, Menoscuarto.

RODRÍGUEZ GUERRERO-STRACHEN, Santiago (1999): Presencia de Edgar Allan Poe en la literatura española del siglo XIX. Valladolid, Universidad de Valladolid.

SANZ RAMÍREZ, José Antonio (2010): Antonio de Hoyos y Vinent: Genealogía y elogio de la pasión. Madrid, Universidad Complutense de Madrid. Tesis Doctoral.

TODOROV, Tzvetan (1970): Introduction à la littérature fantastique. París, Edition du Seuil, Trad.esp.: Introducción a la literatura fantástica. Buenos Aires, Tiempo Contemporáneo, 1972.

TODOROV, Tzvetan (2001): "Definición de lo fantástico". En David ROAS (ed.): Teorías de lo fantástico. Madrid, Arco/Libros.

VAX, Louis (1960): Arte y literatura fantásticas. Trad. Juan Merino. Buenos Aires, Editorial Universitaria de Buenos Aires [1965].

(C) Mohamed Ben Slama

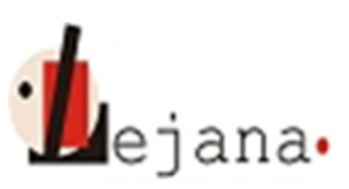

http://lejana.elte.hu

Universidad Eötvös Loránd, Departamento de Español, 1088 Budapest, Múzeum krt. 4/C

Recibido: 23 de marzo de 2016

Aceptado: 01 de mayo de 2016 